\title{
Multiresistant Bacterial Pathogens Causing Bacterial Pneumonia and Analyses of Potential Risk Factors from Northeast Ethiopia
}

\author{
Tewodros Dessie $\left(\mathbb{D},{ }^{1}\right.$ Mohabaw Jemal $\left(\mathbb{D},{ }^{2}\right.$ Minwuyelet Maru $\mathbb{D}^{1},{ }^{1}$ and Moges Tiruneh ${ }^{2}$ \\ ${ }^{1}$ Amhara Public Health Institute, Dessie Branch, P.O. Box 686, Dessie, Ethiopia \\ ${ }^{2}$ University of Gondar, College of Medicine and Health Sciences, School of Biomedical and Laboratory Sciences, \\ Department of Medical Microbiology, P.O. Box 196, Gondar, Ethiopia \\ Correspondence should be addressed to Tewodros Dessie; tedydes21@gmail.com
}

Received 27 November 2020; Revised 25 February 2021; Accepted 1 March 2021; Published 9 March 2021

Academic Editor: Luigi Santacroce

Copyright (c) 2021 Tewodros Dessie et al. This is an open access article distributed under the Creative Commons Attribution License, which permits unrestricted use, distribution, and reproduction in any medium, provided the original work is properly cited.

\begin{abstract}
Background. Pneumonia is the most common cause of morbidity and mortality in developing countries, mostly caused by different species of bacterial pathogens. Hence, patient management needs awareness of the pathogens and antimicrobial susceptibility testing (AST). This study was aimed to assess the type of bacterial isolates and their antimicrobial susceptibility patterns among pneumonia suspected patients at Dessie Referral Hospital, Northeast Ethiopia. Potential risk factors were also assessed to apply preventive measures accordingly. Materials and Methods. A cross-sectional study design was employed among pneumonia suspected patients from February to April 2020 at Dessie Referral Hospital. Sociodemographic characteristics and associated risk factors were collected using a pretested questionnaire, and clinical data were extracted by reviewing medical records. Sputum specimens were collected and inoculated into chocolate agar, blood agar, mannitol salt agar, and MacConkey agar which are then incubated at $35^{\circ} \mathrm{C}$ or $37^{\circ} \mathrm{C}$ for $24-48$ hours. Bacterial species were identified based on Gram stain, colony characteristics, and biochemical techniques. The data were entered in to Epi-Info version 7.1 .5 and analyzed with SPSS software version 20. $p$ value $<0.05$ at $95 \%$ CI was considered as statistically significant. Results. A total of 406 sputum specimens were collected and cultured, among which 157 (38.7\%) were positive for different bacterial pathogens. The predominant pathogens were Klebsiella pneumoniae (28.0\%), Streptococcus pneumoniae (24.8\%), Staphylococcus aureus (18.5\%), and Pseudomonas aeruginosa (14.0\%). Majority of the isolates exhibited resistance to ampicillin with $81.5 \%$ followed by penicillin with $75.9 \%$ and amoxicillin-clavulanate with $61.2 \%$. Multivariable logistic regression showed a significant association of culture positivity with older age $(\mathrm{AOR}=2.43, \mathrm{CI}: 1.12-5.28, p$ value $=0.025)$, cigarette smoking $(\mathrm{AOR}=4.67, \mathrm{CI}: 2.39-9.20, p$ value $<0.001)$, and alcohol use $(\mathrm{AOR}=5.58, \mathrm{CI}: 3.14-9.92, p$ value $<0.001)$. Resistance to ampicillin and penicillin was associated with repeated prescription and use. Conclusions. This study found high prevalence of bacterial pneumonia in the study area, and high rate of bacterial resistance was observed in ampicillin, penicillin, and amoxicillin-clavulanate. Repeated prescriptions and use of antimicrobials were significantly independent factors of bacterial resistance. Therefore, patient management needs identification of bacteria by routine culture with antimicrobial susceptibility testing.
\end{abstract}

\section{Introduction}

Pneumonia, supported with a clinical and/or radiological consolidation of the lungs, is an inflammation (acute or chronic) of the lung parenchyma [1]. This inflammation is produced mostly by microorganisms, particularly bacteria $[2,3]$. The extracellular bacteria responsible for pneumonia include S. pneumoniae, H. influenzae, and Staphylococcus aureus, while Pseudomonas aeruginosa and other Gramnegative bacilli are infrequent causes of the disease. Moreover, the "atypical" intracellular bacteria responsible for this disease, without being cultured by routine culture methods, include Mycoplasma pneumoniae, Chlamydophila pneumoniae, and Legionella pneumophila [4]. Pneumonia can be transmitted by different ways, inhalation of droplets (e.g., C. pneumoniae and M. pneumoniae), environmentally 
(L. pneumophila), and microaspiration of a potential pathogen after colonization of the nasopharynx (e.g., $S$. pneumoniae, $H$. influenzae, or S. aureus) [4]. In all ways, the infection of the pulmonary parenchyma leads the bronchioles and alveoli to be filled with inflammatory exudates. It leads to a decrease of carbon dioxide and oxygen exchange between blood and the lungs and causes respiratory scarcity, making it hard for infected persons to breathe $[5,6]$.

To make selection of initial antimicrobial therapies easier, the disease is usually classified as community-acquired pneumonia (CAP) or healthcare-associated pneumonia (HCAP) [7]. There is high prevalence of multidrug-resistant (MDR) pathogens in healthcare settings, HCAP patients receiving broad empiric therapies [7]. Moreover, the clinical presentations for both types of the disease may range from mild pneumonia (fever and productive cough) to severe pneumonia (respiratory distress and sepsis) [8, 9]. In developing countries, pneumonia is the most common cause of illness in adults visiting hospitals [10]. The disease also affects children and elders in a high proportion [11]. This indicates that pneumonia is among the leading causes of morbidity and mortality in all age groups [12]. Globally, the increase in the burden of bacterial pneumonia with age needs more attention to the disease in the future [13]. In addition, pneumonia causes crisis in terms of health expenses and days of work lost [14]. As indicated by several studies, high incidence, admission, and mortality rates of bacterial pneumonia are contributing factors for both health crisis and economic burdens $[13,15,16]$. Moreover, severe pneumonia can cause long-term complications such as bronchiectasis which may persist to chronic obstructive lung disease [17].

Key factors for the development of the disease reported by several studies were aging, smoking, alcoholism, chronic obstructed pulmonary diseases (COPD), hospitalization for long periods, chronic disease, immunodeficiency, contact with contaminated hospital materials, and exposure to antibiotics for a long period and viral infections of the respiratory tract, as it compromises the respiratory tract and results in bacterial colonization and infection [18-22].

Globally, community-acquired pneumonia (CAP) causes approximately 31.1 per 100000 deaths in people less than 19 years [23]. The global annual incidence rate of CAP in the age group of $18-39$ and $\geq 75$ years is $6 / 1000$ and $34 / 1000$, respectively. Among all cases, $20-40 \%$ of patients need admission, from which $5-10 \%$ of them are admitted to intensive care units due to severe complications such as septic shock, extrapulmonary organ dysfunction, and acute respiratory distress syndrome (ARDS). Moreover, the overall mortality among adults from CAP is $6-15 \%$, which magnifies the importance of identifying and treating patients with this disease [24-26]. In the United States, 5 million to 10 million patients are treated for community-acquired pneumonia (CAP) annually [27], with greater than $\$ 10$ billion medical costs [28]. In Africa, the mortality rate of adult patients was in the range of $6 \%$ and $15 \%$ [29]. In South Africa, CAP was the fifth largest killer, accounting 3.9\% of all deaths [30]. Based on previous reports, the prevalence of CAP in Ethiopia was in the range of $40-48 \%$ [12, 31-34].
In developing countries, bacterial pneumonia is treated usually empirically; by medical history and physical examinations, the etiologic agent is rarely identified [35] and results in high prevalence of multidrug-resistant (MDR) pathogens [7]. Hence, identifying the most common bacterial pathogens and their antimicrobial susceptibility patterns timely and accurately is key to reduce morbidity and mortality due to the disease [36], as the empiric treatment is based on severity of pneumonia, the prevalence, and local antimicrobial resistance patterns [22, 37, 38].

Therefore, awareness about the etiology of pneumonia is fundamental for appropriate patient management. In Northeast Ethiopia, however, there was scarce of studies showing the real burden of bacterial pneumonia among suspected patients. In addition, there are scarce of studies about antimicrobial susceptibility patterns of the common bacterial agents for pneumonia. Therefore, this study aimed to assess the prevalence of bacterial pathogens, their antimicrobial susceptibility patterns, and associated risk factors among patients suspected for bacterial pneumonia attending Dessie Referral Hospital, Northeast Ethiopia.

\section{Materials and Methods}

2.1. Study Design and Setting. A hospital-based crosssectional study was conducted from February to April 2020 in Dessie Referral Hospital, Northeast Ethiopia. The hospital had around 500 beds with annual ambulatory cases of around 14400; hence, it was purposefully selected to conduct this study. All pneumonia suspected patients visiting the hospital were used as the source population, and all patients aged $\geq 5$ years who were clinically suspected for bacterial pneumonia were included in the study. Patients who were under antimicrobial treatment within the last 14 days during data collection were excluded from the study. Pneumonia prevalence of $40.3 \%$ from the previous study was used to determine the number of study participants [1].

2.2. Sample Size and Sampling Technique. A total of 406 study participants were proposed and systematically recruited.

2.3. Data Collection. Data related to sociodemography and risk factors for bacterial pneumonia were collected by pretested and structured questionnaire through face-to-face interview. Gene Xpert results, initial diagnosis, and nutritional status of study participants were collected by reviewing medical records. Pneumonia suspected patients were clinically selected based on chest pain, shortness of breath, cough with sputum production, fever, night sweats, shaking chills, hemoptysis, and altered mental state (confusion). Sputum specimens were collected in a sterile, disposable, leak proof, and wide-mouthed container with tight-fitting lid. To reduce the number of commensals, the purulent parts of the sputum specimens were washed in about $5 \mathrm{ml}$ of sterile physiological saline. To keep pathogens (such as S. pneumoniae and $H$. influenzae) alive, the washed sputum specimens were 
inserted to a cotton-wool swab which then inserted in containers of Amies transport medium; then, all specimens were transported with cold box to Amhara Public Health Institute (APHI), Dessie Branch Bacteriology Laboratory for culture and antimicrobial susceptibility testing.

2.4. Bacterial Isolation and Identification. All specimens received for culture were evaluated macroscopically followed by microscopic inspection by Gram stain before culture analysis began. Thus, sputum specimens with at least 25 polymorph-nuclear leukocytes and $<10$ epithelial cells per low power field and $>10$ bacteria per high-powered field were processed for culture [39-41].

The sputum specimens appropriate for culture were inoculated into blood agar plate (BAP), MacConkey agar plate (MAC), mannitol salt agar (MSA), and chocolate agar plate $(\mathrm{CHO})$. Subsequently, BAP, MAC, and MSA were incubated at $37^{\circ} \mathrm{C}$ for $18-24$ hours, while $\mathrm{CHO}$ (in humid, $5 \% \mathrm{CO}_{2}$ atmosphere) was incubated for 18-24 hours at $35^{\circ} \mathrm{C}-37^{\circ} \mathrm{C}$. All the plates were examined for growth after 24 hours; the plates without growth were further incubated for up to $48 \mathrm{hrs}$. The colonies were subcultured on BAP and MAC for further identification. Bacterial species were identified based on Gram stain, colony characteristics (such as size, shape, pigmentation, and color) zones of hemolysis, and other biochemical characteristics. Streptococcus pneumoniae was identified by catalase and optochin $(5 \mu \mathrm{g})$ sensitivity tests, while $S$. aureus isolates were confirmed by catalase, coagulase, and the mannitol fermentation tests. Chocolate agar, enriched with factor $\mathrm{V}(\mathrm{NAD})$ and factor $\mathrm{X}$ (hemi), was used to enhance the growth of $H$. influenzae. Gram-negative isolates were inoculated onto different biochemical tests such as motility, indole, urea, lysine decarboxylase, triple sugar iron agar, and citrate utilization tests for identification [42].

2.5. Antimicrobial Susceptibility Testing. Antimicrobial susceptibility testing (AST) for bacterial isolates was performed according to Clinical and Laboratory Standards Institute' (CLSI) recommendations [43]. The applied discs were tetracycline (TE_30 $\mu \mathrm{g})$, erythromycin (E_15 $\mu \mathrm{g}$ ), penicillin $\left(\mathrm{P}_{-} 10 \mu \mathrm{g}\right)$, ceftriaxone (CRO_30 $\left.\mu \mathrm{g}\right)$, doxycycline (DA_30 $\mu \mathrm{g}$ ), trimethoprim-sulphamethoxazole (TMPSMX_1.25 $+23.75 \mu \mathrm{g}$ ), ciprofloxacin (CIP_5 $\mu \mathrm{g})$, gentamicin $\left(\mathrm{CN}_{-} 10 \mu \mathrm{g}\right), \quad$ ampicillin $\quad\left(\mathrm{AMP}_{-} 10 \mu \mathrm{g}\right)$, imipenem (IMP_10 $\mu \mathrm{g}$ ), cefepime (PEP_30 $\mu \mathrm{g}$ ), amoxicillin/clavulanic acid (AMC_20/10 $\mu \mathrm{g}$ ), piperacillin/tazobactam (TZP_100/ $10 \mu \mathrm{g}$ ), amikacin (AK_30 $\mu \mathrm{g}$ ), cefuroxime (CXM_30 $\mu \mathrm{g}$ ), ceftazidime (CAZ_30 $\mu \mathrm{g})$, chloramphenicol (CAF_30 $\mu \mathrm{g})$, meropenem (MER_10 $\mathrm{g}$ ), aztreonam (AZT_30 $\mu \mathrm{g}$ ), oxacillin (OXA_1 $\mu \mathrm{g}$ ), and cefoxitin (CXT_30 $\mu \mathrm{g}$ ).

A young culture growth of bacterial suspensions was prepared by picking parts of similar colonies with a sterile wire loop in which these suspensions were adjusted to McFarland 0.5 turbidity standard. The bacterial suspensions in a sterile broth were incubated up to 2 hours to allow the bacteria to reach their log-phase in growth. Then, inoculums were swabbed on to Muller-Hinton agar. After drying the agar for 3-5 minutes, the antimicrobial impregnated disks were placed with sterile forceps on the agar surface in such a way that each disk was placed at least $24 \mathrm{~mm}$ away from each other to avoid the overlapping zone of inhibition. After placing the discs, the plates were allowed to stand for 30 minutes to help the antimicrobial to be dissolved in the media. Following inverting and incubating for 24 hours at $37^{\circ} \mathrm{C}$, the plates were read for the diameter of zone of inhibition. The susceptibility patterns were graded as sensitive, intermediate, and resistant. Muller-Hinton agar (MHA) supplied with 5\% sheep blood was used for S. pneumoniae, while Muller-Hinton agar containing 1.0\% hemoglobin and $1.0 \%$ IsoVitaleX supplement (CHOC-MHA) was used for H. influenzae [42].

2.6. Laboratory Quality Control. Manufacturer instructions and bacteriological standard procedures were followed strictly throughout the whole technical processes including culture media preparation, inoculation, and AST testing. The sterility of culture media was checked by incubating $5 \%$ of the batch at $35-37^{\circ} \mathrm{C}$ overnight and was evaluated for possible contamination. The standard reference bacterial strains such as $S$. aureus (ATCC $\left.{ }^{\circledR} 25923\right), H$. influenzae (ATCC ${ }^{\circledR}$ 49247), E. coli (ATCC ${ }^{\circledR}$ 35218), and S. pneumoniae (ATCC $\left.{ }^{\circledR} 49619\right)$ were used as a quality control [43].

2.7. Data Quality Control. Training was given for the data collector about data collection procedures and interview techniques. To assure the quality of the data, a pretested, structured questionnaire was used for data collection. The questionnaire was objective-based and logically sequenced. It was checked daily by the principal investigator for its completeness.

2.8. Data Analysis. Data were checked for completeness, cleaned, coded, and entered in to Epi-Info version 7.1 software and then exported to SPSS version 20 for analysis. Frequency, proportions, and summary statistics were used to describe study participants in relation to relevant variables. Bivariate and multivariate logistic regression analyses were carried out to identify the association between bacterial pathogens, antimicrobial resistance, and possible risk factors. Odds ratio and $p$ value were used to assess the presence and degree of association. $p$ value $<0.05$ at $95 \%$ CI was considered as statistically significant.

2.9. Ethical Approval and Consent to Participate. Ethical clearance was obtained from University of Gondar, College of Medicine and Health Sciences Institutional Review Board. Informed written consent was obtained from the study participants after explaining the purpose and objective of the study. The laboratory results from the study participants were communicated to their physicians for appropriate patient management. Data from all patients were kept confidential.

2.10. Limitations of the Study. This study did not consider the "atypical" intracellular bacteria, such as Mycoplasma pneumoniae, Chlamydophila pneumoniae, and Legionella 
pneumophila, since they cannot be cultured by routine culture methods. This study did not also consider the anaerobic bacteria (Prevotella spp., Fusobacterium spp., and Clostridium spp.) as routine culture methods are mostly aerobic. Hence, it underestimates the actual prevalence in the study area. This study did not include serotyping techniques to Haemophilus influenzae and Streptococcus pneumoniae. Characterization of methicillin-resistant Staphylococcus aureus (MRSA) was not performed.

\section{Results}

3.1. Sociodemographic and Clinical Data Characteristics. This study was conducted among 406 pneumonia suspected patients, of which 221 (54.4\%) were males and 249 (61.3\%) were urban dwellers with 158 (38.9\%) participants unable to read and write (Table 1 ). The median age of study participants was 45.0 with a range of 10-95 years. Among study participants, 131 (32.3\%) were smokers and 158 (38.9\%) were alcohol consumers.

Among all participants, 43 (10.6\%) were HIV positives and 39 (9.6\%) had active TB cases at the time of data collection. As indicated in Table 1, asthma, diabetes, and hypertension comorbidities accounted $6 \%, 5 \%$, and $3 \%$, respectively. The nutritional status of children $(n=30)$ was assessed by mid-upper arm circumferences (MUAC) and body mass index (BMI), all of which $(n=30,100 \%)$ showed normal nutritional status.

3.2. Prevalence of Bacterial Pathogens. Bacterial isolates were identified from 157 (38.7\%) participants, of which 155 (98.7\%) were identified as community-acquired pneumonia (CAP) while $2(1.3 \%)$ were hospital-acquired pneumonia (HAP). Gram-negative isolates accounted 89 (56.7\%), while the rest $68(43.3 \%)$ were Gram-positive. The frequently isolated pathogens were Klebsiella pneumoniae, Streptococcus pneumoniae, Staphylococcus aureus, Pseudomonas aeruginosa, Haemophilus influenzae, Escherichia coli, Acinetobacter baumannii, and Klebsiella oxytoca with frequencies of $44(28.0 \%), 39$ (24.8\%), 29 (18.5\%), 22 (14.0\%), $11(7.0 \%), 7(4.5 \%), 3(1.9 \%)$, and $2(1.3 \%)$, respectively (Table 2). Additionally, all study participants were screened for TB, by Gene Xpert and Mycobacterium tuberculosis was detected in 39 (9.6\%) of the participants. Among TB-positive participants, rifampicin-resistant was detected in $5(12.8 \%)$ of the cases.

3.3. Antimicrobial Susceptibility Patterns of Bacterial Isolates. Among Gram-negative isolates, resistance to tetracycline, amoxicillin-clavulanate, co-trimoxazole, and chloramphenicol for Klebsiella pneumoniae, which was the most frequently isolated species, was $93.2 \%, 88.6 \%, 88.6 \%$, and $79.5 \%$, respectively. Whereas low resistance to ciprofloxacin (2.3\%), cefuroxime (4.5\%), piperacillin-tazobactam $(4.5 \%)$, ceftazidime (6.8\%), and amikacin $(9.1 \%)$ was observed for Klebsiella pneumoniae isolates. Pseudomonas aeruginosa isolates showed more resistance to ceftazidime (63.6\%) and gentamicin (54.5\%), while Haemophilus influenzae isolates
TABLE 1: Sociodemographic characteristics and clinical data of pneumonia suspected patients, Dessie, 2020.

\begin{tabular}{|c|c|c|}
\hline Characteristics & Frequency & Percentage $(\%)$ \\
\hline \multicolumn{3}{|l|}{ Sex } \\
\hline Male & 221 & 54.4 \\
\hline Female & 185 & 45.6 \\
\hline \multicolumn{3}{|l|}{ Age (in years) } \\
\hline $5-14$ & 30 & 7.4 \\
\hline $15-24$ & 57 & 14.0 \\
\hline $25-44$ & 96 & 23.6 \\
\hline $45-64$ & 67 & 27.6 \\
\hline$>64$ & 156 & 38.4 \\
\hline \multicolumn{3}{|l|}{ Residence } \\
\hline Urban & 249 & 61.3 \\
\hline Rural & 157 & 38.7 \\
\hline \multicolumn{3}{|l|}{ Educational level } \\
\hline Unable to read and write & 158 & 38.9 \\
\hline Read and write only & 48 & 11.8 \\
\hline Primary education & 56 & 13.8 \\
\hline Secondary education & 67 & 16.5 \\
\hline College and above & 77 & 19.0 \\
\hline \multicolumn{3}{|l|}{ Marital status } \\
\hline Married & 187 & 46.1 \\
\hline Single & 107 & 26.4 \\
\hline Divorced & 70 & 17.2 \\
\hline Widowed & 42 & 10.3 \\
\hline \multicolumn{3}{|l|}{ Occupational status } \\
\hline Employed & 49 & 12.1 \\
\hline Unemployed & 120 & 29.6 \\
\hline Farmer & 161 & 39.7 \\
\hline Others & 76 & 18.7 \\
\hline \multicolumn{3}{|l|}{ HIV } \\
\hline Positive & 43 & 10.6 \\
\hline Negative & 383 & 89.4 \\
\hline \multicolumn{3}{|l|}{ TB } \\
\hline Positive & 39 & 9.6 \\
\hline Negative & 385 & 90.4 \\
\hline \multicolumn{3}{|l|}{ Asthma } \\
\hline Yes & 23 & 6.0 \\
\hline No & 383 & 94.0 \\
\hline \multicolumn{3}{|l|}{ Diabetes } \\
\hline Yes & 20 & 5.0 \\
\hline No & 386 & 95.5 \\
\hline \multicolumn{3}{|l|}{ Hypertension } \\
\hline Yes & 13 & 3.0 \\
\hline No & 393 & 93.0 \\
\hline Total & 406 & 100 \\
\hline
\end{tabular}

were more resistant to tetracycline (90.9\%) and ampicillin (54.5\%) (Table 3).

Among Gram-positive isolates, Streptococcus pneumoniae, the second most frequent isolate of all species, showed higher resistance to oxacillin (56.4\%), penicillin (56.4\%), and erythromycin (48.7\%), while it showed lower resistance to clindamycin (10.3\%), co-trimoxazole (12.5\%), and ciprofloxacin (17.9\%). Staphylococcus aureus resist more to tetracycline $(86.2 \%)$ and co-trimoxazole (72.4\%) (Table 4). Moreover, the prevalence of methicillin-resistant Staphylococcus aureus (MRSA) was found to be $34.5 \%(n=10)$. 
TABLe 2: The prevalence of bacterial isolates identified from pneumonia suspected patients, Dessie, 2020.

\begin{tabular}{lcc}
\hline Bacterial isolates & Frequency & Percentage \\
\hline Gram-positive $(n=68)$ & & 39 \\
S. pneumoniae & 29 & 24.8 \\
S. aureus & & 18.5 \\
Gram-negative $(n=89)$ & 44 & 28.0 \\
K. pneumoniae & 22 & 14.0 \\
P. aeruginosa & 11 & 7.0 \\
H. influenzae & 7 & 4.5 \\
E. coli & 3 & 1.9 \\
A. baumannii & 2 & 1.3 \\
K. oxytoca & $\mathbf{1 5 7}$ & $\mathbf{3 8 . 7}$ \\
Overall &
\end{tabular}

TABle 3: Antimicrobial resistance profile of bacterial isolates, Dessie, 2020.

\begin{tabular}{|c|c|c|c|c|c|c|c|c|c|c|c|c|c|c|c|c|}
\hline \multirow{2}{*}{ GP isolates } & \multicolumn{10}{|c|}{ Antimicrobials tested } & & & & & & \\
\hline & E & OXA & $\mathrm{TE}$ & COT & DA & $\mathrm{CN}$ & $\mathrm{P}$ & CXT & $\mathrm{C}$ & CIP & & & & & & \\
\hline $\begin{array}{l}\text { S. pneumoniae } \\
(n=39)\end{array}$ & $\begin{array}{c}19 \\
(48.7)\end{array}$ & $\begin{array}{c}22 \\
(56.4)\end{array}$ & $\begin{array}{c}16 \\
(41.0)\end{array}$ & $\begin{array}{c}5 \\
(12.8)\end{array}$ & $\begin{array}{c}4 \\
(10.3)\end{array}$ & NT & NT & NT & NT & NT & & & & & & \\
\hline $\begin{array}{l}\text { S. aureus } \\
(n=29)\end{array}$ & $\begin{array}{c}14 \\
(48.3)\end{array}$ & NT & $\begin{array}{c}25 \\
(86.2)\end{array}$ & $\begin{array}{c}21 \\
(72.4)\end{array}$ & $\begin{array}{c}3 \\
(10.3)\end{array}$ & $\begin{array}{c}8 \\
(27.6)\end{array}$ & $\begin{array}{c}22 \\
(75.9)\end{array}$ & $\begin{array}{c}10 \\
(34.5)\end{array}$ & $\begin{array}{c}8 \\
(27.6)\end{array}$ & $\begin{array}{c}7 \\
(24 .)\end{array}$ & & & & & & \\
\hline GN isolates & AMP & AMC & $\mathrm{TZP}$ & CRO & $\mathrm{AK}$ & $\mathrm{CXM}$ & CIP & COT & $\mathrm{CN}$ & IMP & GAZ & $\mathrm{TE}$ & c & PEP & MER & AZT \\
\hline $\begin{array}{l}\text { K. pneumoniae } \\
(n=44)\end{array}$ & $\begin{array}{c}44 \\
(100)\end{array}$ & $\begin{array}{c}39 \\
(88.6)\end{array}$ & $2(4.5)$ & $\begin{array}{c}6 \\
(13.6)\end{array}$ & $\begin{array}{c}4 \\
(9.1)\end{array}$ & $\begin{array}{c}2 \\
(4.5)\end{array}$ & $1(2.3)$ & $\begin{array}{c}39 \\
(88.6)\end{array}$ & $\begin{array}{c}7 \\
(15.9)\end{array}$ & $\begin{array}{c}6 \\
(13.6)\end{array}$ & $3(6.8)$ & $\begin{array}{c}42 \\
(95.5)\end{array}$ & $\begin{array}{c}35 \\
(79.5)\end{array}$ & NT & NT & NT \\
\hline $\begin{array}{l}P . \text { aeruginosa } \\
(n=22)\end{array}$ & NT & NT & $2(9.1)$ & NT & $\begin{array}{c}2 \\
(9.1)\end{array}$ & NT & $1(4.5)$ & NT & $\begin{array}{c}12 \\
(54.5)\end{array}$ & $\begin{array}{c}1 \\
(4.5)\end{array}$ & $\begin{array}{c}14 \\
(63.6)\end{array}$ & NT & NT & $\begin{array}{c}2 \\
(9.1)\end{array}$ & NT & NT \\
\hline $\begin{array}{l}\text { H. influenzae } \\
(n=11)\end{array}$ & $\begin{array}{c}6 \\
(54.5)\end{array}$ & $0(0)$ & NT & $\begin{array}{c}4 \\
(36.4)\end{array}$ & NT & NT & $\begin{array}{c}4 \\
(36.4)\end{array}$ & NT & NT & NT & NT & $\begin{array}{c}10 \\
(90.9)\end{array}$ & NT & NT & $0(0)$ & $0(0)$ \\
\hline E. $\operatorname{coli}(n=7)$ & $\begin{array}{c}5 \\
(71.4)\end{array}$ & $\begin{array}{c}3 \\
(42.9)\end{array}$ & $\begin{array}{c}1 \\
(14.3)\end{array}$ & $\begin{array}{c}1 \\
(14.3)\end{array}$ & $\begin{array}{c}1 \\
(14.3)\end{array}$ & $\begin{array}{c}1 \\
(14.3)\end{array}$ & $0(0)$ & $\begin{array}{c}5 \\
(71.4)\end{array}$ & $\begin{array}{c}1 \\
(14.3)\end{array}$ & $\begin{array}{c}1 \\
(14.3)\end{array}$ & $\begin{array}{c}1 \\
(14.3)\end{array}$ & $\begin{array}{c}5 \\
(71.4)\end{array}$ & $\begin{array}{c}5 \\
(71.4)\end{array}$ & NT & NT & NT \\
\hline $\begin{array}{l}\text { A. baumannii } \\
(n=3)\end{array}$ & NT & NT & $\begin{array}{c}2 \\
(66.7)\end{array}$ & NT & $\begin{array}{c}1 \\
(33.3)\end{array}$ & NT & $\begin{array}{c}2 \\
(66.7)\end{array}$ & $\begin{array}{c}2 \\
(66.7)\end{array}$ & $\begin{array}{c}2 \\
(66.7)\end{array}$ & NT & $\begin{array}{c}2 \\
(66.7)\end{array}$ & $\begin{array}{c}2 \\
(66.7)\end{array}$ & NT & $\begin{array}{c}2 \\
(66.7)\end{array}$ & $\begin{array}{c}1 \\
(33.3)\end{array}$ & NT \\
\hline $\begin{array}{l}\text { K. oxytoca } \\
(n=2)\end{array}$ & $\begin{array}{c}2 \\
(100) \\
\end{array}$ & $1(50)$ & $0(0)$ & $0(0)$ & $0(0)$ & $1(50)$ & $0(0)$ & $1(50)$ & $0(0)$ & $0(0)$ & $0(0)$ & $2(50)$ & $\begin{array}{c}2 \\
(100)\end{array}$ & NT & NT & NT \\
\hline
\end{tabular}

Note: GP, Gram-positive; GN, Gram-negative; E, erythromycin; OXA, oxacillin; DA, clindamycin; P, penicillin; CXT, cefoxitin; AMP, ampicillin; AMC, amoxicillin/clavulanate; TZP, piperacillin/tazobactam; CRO, ceftriaxone; AK, amikacin; CXM, cefuroxime; CIP, ciprofloxacin; COT, co-trimoxazole; CN, gentamicin; IMP, imipenem; CAZ, ceftazidime; TE, tetracycline; C, chloramphenicol; PEP, cefepime; MER, meropenem; AZT, aztreonam; NT, not tested (based on CLSI-2019 Guideline).

TABLE 4: Multidrug resistance (MDR) profile of the isolated organisms, Dessie, 2020.

\begin{tabular}{|c|c|c|c|c|c|c|c|c|c|c|}
\hline \multirow{2}{*}{ Bacterial isolates $(n)$} & \multicolumn{10}{|c|}{ Degree of resistance } \\
\hline & R0 (\%) & R1 (\%) & R2 (\%) & R3 (\%) & $\mathrm{R} 4(\%)$ & R5 (\%) & R6 (\%) & R7 (\%) & R8 (\%) & Total MDR $(\geq \mathrm{R} 3)$ \\
\hline K. pneumoniae $(n=44)$ & $0(0)$ & $0(0)$ & $1(2.3)$ & $5(11.4)$ & $5(11.4)$ & $16(36.4)$ & $11(25.0)$ & $4(9.1)$ & $2(4.5)$ & $43(97.7)$ \\
\hline S. pneumoniae $(n=39)$ & $01(2.6)$ & $15(38.5)$ & $19(48.7)$ & $2(5.1)$ & $2(5.1)$ & $0(0)$ & $0(0)$ & $0(C$ & $0(0)$ & 4 \\
\hline S. aureus $(n=29)$ & $0(0)$ & & & $4(13.8)$ & $12(41.4)$ & & $5(17.2)$ & $0(0)$ & $0(0)$ & \\
\hline$P$. aeruginosa $(n=22)$ & $0(0)$ & $5(22.7)$ & $7(31.8)$ & $6(27.3)$ & $2(9.1)$ & $2(9.1)$ & $0(0)$ & $0(0)$ & $0(0)$ & $10(45.5)$ \\
\hline H. influenzae $(n=11)$ & $1(9.1)$ & $5(45.5)$ & $1(9.1)$ & $0(0)$ & $4(36.4)$ & $0(0)$ & $0(0)$ & $0(0)$ & $0(0)$ & $4(36.4)$ \\
\hline E. $\operatorname{coli}(n=7)$ & $0(0)$ & $0(0)$ & $0(0)$ & $2(28.6)$ & $2(28.6)$ & $2(28.6)$ & $0(0)$ & $0(0)$ & $1(14.3)$ & $7(100)$ \\
\hline A. baumannii $(n=3)$ & $0(0)$ & $0(0)$ & $0(0)$ & $0(0)$ & $0(0)$ & $1(33.3)$ & $2(66.7)$ & $0(0)$ & $0(0)$ & $3(100)$ \\
\hline K. oxytoca $(n=2)$ & $0(0)$ & $0(0)$ & $0(0)$ & $0(0)$ & $1(50)$ & $1(50)$ & $0(0)$ & $0(0)$ & $0(0)$ & $2(100)$ \\
\hline
\end{tabular}

Note: R0, susceptible to all antibiotics; R1-R8, resistance to $1,2,3,4,5,6,7$, and 8 antibiotics; $\geq \mathrm{R} 3$, resistance to 3 or more antibiotics; MDR, multidrug resistance.

Multidrug resistance (MDR), resistance to 3 or more antimicrobials, was observed in $99(63.1 \%)$ of the isolates, and high level of MDR was observed among Klebsiella pneumoniae (97.7\%) and Staphylococcus aureus (89.7\%), followed by Pseudomonas aeruginosa (45.5\%) and Haemophilus influenzae (36.4\%) (Table 4).
3.4. Factors Associated with Culture Positivity and Antimicrobial Resistance. Multivariable logistic regression indicated that aging $(\mathrm{AOR}=2.43$; 95\% CI: $1.12-5.28, p=0.025)$, cigarette smoking $(\mathrm{AOR}=4.67,95 \% \mathrm{CI}: 2.39-9.20$, $p$ value $<0.001)$, and alcohol consumption $(\mathrm{AOR}=5.58,95 \%$ CI: 3.14-9.92, $p$ value $<0.001)$ were significantly associated with culture positivity (Table 5). 
TABLe 5: Multivariable logistic regression analysis of culture positivity identified from pneumonia suspected patients, Dessie, 2020.

\begin{tabular}{|c|c|c|c|c|c|c|}
\hline \multirow{2}{*}{ Variables } & \multicolumn{2}{|c|}{ Culture positivity } & \multirow{2}{*}{ COR $(95 \% \mathrm{CI})$} & \multirow{2}{*}{$p$ value } & \multirow{2}{*}{ AOR (95\% CI) } & \multirow{2}{*}{$p$ value } \\
\hline & Positive, $N(\%)$ & Negative, $N(\%)$ & & & & \\
\hline \multicolumn{7}{|c|}{ 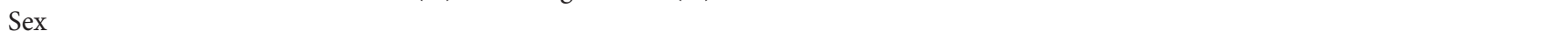 } \\
\hline Female & $59(32)$ & $126(68)$ & 1 & & 1 & \\
\hline Male & $98(44)$ & $123(56)$ & $1.70(1.13-2.56)$ & 0.011 & $0.87(0.44-1.72)$ & 0.678 \\
\hline \multicolumn{7}{|c|}{ Age (years) } \\
\hline $5-15$ & $3(10)$ & $27(90)$ & 1 & & 1 & \\
\hline $15-24$ & $13(23)$ & $44(77)$ & $2.70(0.68-10.19)$ & 0.154 & $0.12(0.02-0.69)$ & 0.017 \\
\hline $25-44$ & $20(21)$ & $76(79)$ & $2.40(0.65-8.61)$ & 0.190 & $0.27(0.10-0.73)$ & 0.010 \\
\hline $44-64$ & $43(64)$ & $24(36)$ & $16.13(4.43-58.76)$ & $<0.001$ & $0.35(0.17-0.75)$ & 0.006 \\
\hline$>64$ & $78(50)$ & $78(50)$ & $9.00(2.62-30.90)$ & $<0.001$ & $2.43(1.12-5.28)$ & 0.025 \\
\hline \multicolumn{7}{|l|}{ Residence } \\
\hline Urban & $100(40)$ & $149(60)$ & 1 & & 1 & \\
\hline Rural & $57(36)$ & $100(64)$ & $0.83(0.55-1.25)$ & 0.365 & $1.04(0.42-2.59)$ & 0.941 \\
\hline \multicolumn{7}{|l|}{ Smoking } \\
\hline No & $67(24)$ & $208(76)$ & 1 & & 1 & \\
\hline Yes & $90(69)$ & $41(31)$ & $6.62(4.19-10.47)$ & $<0.001$ & $4.67(2.39-9.20)$ & $<0.001$ \\
\hline \multicolumn{7}{|c|}{ Alcohol drinking } \\
\hline No & $104(66)$ & $54(34)$ & 1 & & 1 & \\
\hline Yes & $53(21)$ & $195(79)$ & $6.54(4.20-10.20)$ & $<0.001$ & $5.58(3.14-9.92)$ & $<0.001$ \\
\hline
\end{tabular}

\section{Discussion}

The increased bacterial infection causing pneumonia and antimicrobial resistance become a serious public health concern. In our study, the overall prevalence of bacterial isolates was $38.7 \%$, consistent with studies from Ethiopia reported by Temesgen et al. [1], Adhanom et al. [12], Regasa et al. [31, 32], and findings from Nigeria reported by Salami et al. [44]. However, the finding in this study was higher than the findings from Brazil, China, and the USA reported by Assunção et al. [5], Lin et al. [45], and Carugati et al. [46], respectively, while it was lower than the findings in other parts of Ethiopia and elsewhere [10, 21, 33, 34, 47-49]. The inconsistency might be explained as real prevalence variations or methodological differences.

Although pneumonia can be caused by a variety of bacterial species, some bacteria are frequent causes due to a variety of reasons. In the present study, the predominant bacterial isolates were Klebsiella pneumoniae (28.0\%) and Streptococcus pneumoniae (24.8\%). These two pathogens were reported as predominant in different studies $[1,10,12,50]$. This predominance may be due to their capsular nature and the emergence of strains from both species that can acquire additional genetic traits $[51,52]$. The prevalence of Staphylococcus aureus and methicillin-resistant Staphylococcus aureus (MRSA) in our study was $18.5 \%$ and $34.5 \%$, respectively. This indicates that MRSA is becoming an important pneumonia-causing pathogen in the study area and supported by other studies $[12,53,54]$.

In line with previously documented results, our finding revealed an increased prevalence of drug-resistant isolates that could possess a significant health risk. Klebsiella pneumoniae was resistant and sensitive to tetracycline and ciprofloxacin in $95.5 \%$ and $97.7 \%$, respectively. It was comparable to the study conducted in Ethiopia by Temesgen et al. with $100 \%$ resistance and $96.7 \%$ sensitivity [1]. Moreover, the sensitivity of this pathogen to ciprofloxacin was comparable with a study conducted in China (91.7\%) [47]. Streptococcus pneumoniae, the second most frequent species in our study, showed resistant to oxacillin in $56.4 \%$, while only $10.3 \%$ of the isolates were resistant to clindamycin. This was comparable with studies conducted in Ethiopia [1, 34]. Moreover, Staphylococcus aureus was resistant to penicillin in $75.9 \%$. Other studies reported comparable findings $[1,5,12]$. Pseudomonas aeruginosa was resistant to gentamicin in 59.1\%, compared with other studies $[1,3,5,10,34]$. The possible explanation of drug resistance variations might be due to difference in distribution of resistance strains in different localities. The decreasing susceptibility might be due to increasing trend of using antibiotics.

The overall prevalence of multidrug-resistant (MDR) isolates in this study was $63.1 \%$ which was in agreement with findings reported from Ethiopia by Regasa et al. (56.7\%) [34] and $54.8 \%$ [32]. In contrast, a study reported by Temesgen et al. identified higher prevalence (76.0\%) [1], and lower results were reported from Mekelle, Ethiopia, by Adhanom et al. (17.9\%) [12] and from China by Luan et al. (24.5\%) [3] which could be due to different reasons $[1,12]$ among which poor drug quality, antibiotic prescribing differences such as misuse and/or incomplete treatment courses of antibiotics, overprescription due to a poor diagnostic set-up, and irrational drug use can be mentioned. In support of this, in this study, almost all cases (99\%) were due to communityacquired pneumonia (CAP) and only $1 \%$ of them were due to hospital-acquired pneumonia (HAP).

Several studies reported aging as a risk factor for bacterial pneumonia. In the present study, the age group of $>64$ years was 2.4 times more likely to have bacterial pneumonia compared to the age group of 5-15 years [55]. Similar findings were reported from Spain [56, 57], Pakistan [49], Japan [58], and the USA [59]. The decline of the immune status in the older age may be the possible reason. On the other hand, other studies reported young age as a risk factor 
for the disease in Ethiopia [12] and Ghana [60]. This suggests that occurrence of high transmission due to crowded-living or presence of undernourishment weakens the immune system of the young population.

In this study, smoking increases the risk of bacterial pneumonia 4.7 times compared to those who were nonsmokers. Likewise, cigarette smoking, as a risk factor for pneumonia, was reported from Kenya [61] and Spain $[55,57]$. This may be due to the fact that smoking decreases the number and, at the same time, the action of cilia facilitating the entry of microorganisms to the respiratory tract $[61,62]$.

Several studies also showed that alcohol consumption increases the risk of bacterial pneumonia. In our study, alcohol consumers (although this study did not identify the level of consumption) were 5.6 times more likely to have bacterial pneumonia compared to those who were nonconsumers. Similarly, other studies conducted in Ethiopia [1, 12], China [47], Spain [57], England [63], and Europe [62] identified alcohol consumption as a risk factor for acquiring bacterial pneumonia. This may be due to the fact that the sedative properties of alcohol minimize oropharyngeal tone that results in a high risk of aspiration of pathogens from the upper respiratory tract. Moreover, high levels of alcohol consumption can alter the alveolar macrophage function, hence withdrawing pulmonary defense against infection. Alcohol depresses cough, decreases endothelial adherence, lowers chemotaxis, and suppresses $\mathrm{B}$ cell and $\mathrm{T}$ cell spreading out which contributes to reduced clearance mechanism of lung cells $[1,12,62,63]$.

\section{Conclusions}

The overall prevalence of bacterial isolates, in this study, was $38.7 \%$. This high prevalence needs expanding routine bacterial culture and antimicrobial susceptibility testing in the study area. The predominant isolates were Klebsiella pneumoniae (28.0\%) and Streptococcus pneumoniae $(24.8 \%)$. This indicates that there is an urgent need of strengthening vaccination practices for Streptococcus pneumoniae. The prevalence of multidrug-resistant (MDR) pathogens was $63.1 \%$. The predominant isolate, Klebsiella pneumonia, was highly resistant to tetracycline in $95.5 \%$, followed by penicillin and amoxicillin/clavulanic acid in $81.5 \%$ and $75.9 \%$, respectively. These high figures, in general, recommend avoiding misuse, incomplete treatment courses, overprescription, and irrational use of antibiotics. Aging, cigarette smoking, and alcohol use were factors associated with culture positivity. Therefore, preventive measures to minimize the risk of the disease should include life-style factors such as smoking and alcohol use. Moreover, strengthening regular surveillance systems are essential for assessing predominant pathogens and antibiotic resistance patterns.

\section{Abbreviations}

APHI: Amhara Public Health Institute

ARDS: Acute respiratory distress syndrome
ART: Antiretroviral treatment

AST: Antimicrobial susceptibility test

ATCC: American Type Culture Collection

BAP: Blood agar plate

BMI: Body mass index

CAP: Community-acquired pneumonia

CHO: Chocolate agar

CLSI: Clinical and Laboratory Standards Institute

COPD: Chronic obstructed pulmonary disease

ESBL: Extended spectrum beta-lactamase

HCAP: Hospital-acquired pneumonia

MAC: MacConkey agar

MDR: Multidrug resistance

MHA: Muller-Hinton agar

MIC: Minimum inhibitory concentration

MRSA: Methicillin-resistant Staphylococcus aureus

MSA: Mannitol salt agar

MUAC: Mid-upper arm circumferences

NAD: Nicotinamide adenine dinucleotide

PCR: Polymerase chain reaction

PCV: Pneumococcal conjugate vaccine.

\section{Data Availability}

The datasets used to support the findings of this study are available from the corresponding author upon request.

\section{Conflicts of Interest}

The authors declare that they have no conflicts of interest.

\section{Authors' Contributions}

TD conceived the research idea and involved in data collection and interpretation of the results. MT and MJ have involved in interpretation of the result and evaluating the scientific content of the study. MM has involved in data analysis and rationalizing the method section and manuscript preparation. All authors read and approved the final manuscript for submission.

\section{Acknowledgments}

This study was supported by Amhara Regional State Health Bureau. The authors would like to thank University of Gondar, Amhara Public Health Institute-Dessie Branch, and Dessie Referral Hospital for their support. The authors also thank Mr. Abdu Hussein for his contribution in the data collection process. Finally, their acknowledgment goes to the study participants.

\section{References}

[1] D. Temesgen, F. Bereded, A. Derbie, and F. Biadglegne, "Bacteriology of community acquired pneumonia in adult patients at Felege Hiwot Referral Hospital, Northwest Ethiopia: a cross-sectional study," Antimicrobial Resistance \& Infection Control, vol. 8, no. 1, p. 101, 2019.

[2] E. N. Savvateeva, A. Y. Rubina, and D. A. Gryadunov, "Biomarkers of community-acquired pneumonia: a key to 
disease diagnosis and management," BioMed Research International, vol. 2019, Article ID 1701276, 20 pages, 2019.

[3] Y. Luan, Y. Sun, S. Duan, P. Zhao, and Z. Bao, "Pathogenic bacterial profile and drug resistance analysis of communityacquired pneumonia in older outpatients with fever," Journal of International Medical Research, vol. 46, no. 11, pp. 45964604, 2018.

[4] J. S. Brown, "Community-acquired pneumonia," Clinical Medicine, vol. 12, no. 6, p. 538, 2012.

[5] R. G. Assunção, W. A. Pereira, F. J. Nogueira, I. L. Dutra, T. M. Novais, and A. G. Abreu, "Antimicrobial resistance of microorganisms causing pneumonia in patients of a public hospital in Brazilian pre-amazon region," Journal of Pharmacy and Pharmacology, vol. 7, pp. 15-21, 2019.

[6] M. Ozsoz, A. U. Ibrahim, S. Serte, F. Al-Turjman, and P. S. Yakoi, "Viral and bacterial pneumonia detection using artificial intelligence in the era of COVID-19," 2020.

[7] A. Bjarnason, H. Asgeirsson, O. Baldursson, K. G. Kristinsson, and M. Gottfredsson, "Mortality in healthcare-associated pneumonia in a low resistance setting: a prospective observational study," Infectious Diseases, vol. 47, no. 3, pp. 130-136, 2015.

[8] J. Almirall, I. Bolibar, and M. Serra-Prat, "Risk factors for community-acquired pneumonia in adults: recommendations for its prevention," Community Acquired Infection, vol. 2, no. 2, p. 32, 2015.

[9] S. Athlin, C. Lidman, A. Lundqvist et al., "Management of community-acquired pneumonia in immunocompetent adults: updated Swedish guidelines 2017," Infectious Diseases, vol. 50, no. 4, pp. 247-272, 2018.

[10] S. Akter, S. M. Shamsuzzaman, and F. Jahan, "Community acquired bacterial pneumonia: aetiology, laboratory detection and antibiotic susceptibility pattern," The Malaysian Journal of Pathology, vol. 36, no. 2, pp. 97-103, 2014.

[11] A. van Gageldonk-Lafeber, P. Wever, I. Van Der Lubben et al., "The aetiology of community-acquired pneumonia and implications for patient management," Netherlands Journal of Medicine, vol. 71, no. 8, pp. 418-425, 2013.

[12] G. Adhanom, D. Gebreegziabiher, Y. Weldu et al., "Species, risk factors, and antimicrobial susceptibility profiles of bacterial isolates from HIV-infected patients suspected to have pneumonia in Mekelle zone, Tigray, northern Ethiopia," BioMed Research International, vol. 2019, Article ID 8768439, 9 pages, 2019.

[13] T. Welte, A. Torres, and D. Nathwani, "Clinical and economic burden of community-acquired pneumonia among adults in Europe," Thorax, vol. 67, no. 1, pp. 71-79, 2012.

[14] A. Torres, N. Lee, C. Cillóniz, J. Vila, and M. Van der Eerden, "Laboratory diagnosis of pneumonia in the molecular age," European Respiratory Journal, vol. 48, no. 6, pp. 1764-1778, 2016.

[15] K. Konomura, H. Nagai, and M. Akazawa, "Economic burden of community-acquired pneumonia among elderly patients: a Japanese perspective," Pneumonia, vol. 9, no. 1, p. 19, 2017.

[16] A. Tichopad, C. Roberts, I. Gembula et al., "Clinical and economic burden of community-acquired pneumonia among adults in the Czech Republic, Hungary, Poland and Slovakia," PLoS One, vol. 8, no. 8, Article ID e71375, 2013.

[17] V. Falcó, J. Burgos, and B. Almirante, "An overview of lefamulin for the treatment of community acquired bacterial pneumonia," Expert Opinion on Pharmacotherapy, vol. 21, no. 6, pp. 629-636, 2020.

[18] M. Mahendra, B. Jayaraj, S. Limaye, S. Chaya, R. Dhar, and P. Mahesh, "Factors influencing severity of community- acquired pneumonia," Lung India: Official Organ of Indian Chest Society, vol. 35, no. 4, p. 284, 2018.

[19] L. H. Shaaban, "Dilemma of community-acquired pneumonia," The Egyptian Journal of Chest Diseases and Tuberculosis, vol. 68 , no. 1, p. 1, 2019.

[20] S. Mythri and H. Nataraju, "Bacteriological profile of community acquired pneumonia," IOSR Journal of Dental and Medical Sciences, vol. 12, pp. 16-19, 2013.

[21] A. Bjarnason, J. Westin, M. Lindh et al., "Incidence, etiology, and outcomes of community-acquired pneumonia: a population-based study," Open Forum Infectious Diseases, Oxford University Press US, Oxford, UK, 2018.

[22] J. P. Metlay, G. W. Waterer, A. C. Long et al., "Diagnosis and treatment of adults with community-acquired pneumonia. An official clinical practice guideline of the American Thoracic Society and Infectious Diseases Society of America," American Journal of Respiratory and Critical Care Medicine, vol. 200, no. 7, pp. e45-e67, 2019.

[23] N. Kassebaum, N. Kassebaum, H. H. Kyu et al., "Child and adolescent health from 1990 to 2015: findings from the global burden of diseases, injuries, and risk factors 2015 study," JAMA Pediatrics, vol. 171, no. 6, pp. 573-592, 2017.

[24] Z. Hoare and W. S. Lim, "Pneumonia: update on diagnosis and management," BMJ, vol. 332, no. 7549, pp. 1077-1079, 2006.

[25] M. Confalonieri, R. Urbino, A. Potena et al., "Hydrocortisone infusion for severe community-acquired pneumonia," American Journal of Respiratory and Critical Care Medicine, vol. 171, no. 3, pp. 242-248, 2005.

[26] C. C. Onyedum and J. C. Chukwuka, "Admission profile and management of community acquired pneumonia in Nigeria-5 year experience in a tertiary hospital," Respiratory Medicine, vol. 105, no. 2, pp. 298-302, 2011.

[27] P. Peyrani, F. W. Arnold, J. Bordon et al., "Incidence and mortality of adults hospitalized with community-acquired pneumonia according to clinical course," Chest, vol. 157, no. 1, pp. 34-41, 2020.

[28] A. Pfuntner, L. M. Wier, and C. Steiner, "Costs for hospital stays in the United States, 2011: statistical brief\# 168," 2014.

[29] W. Wiersinga, M. J. Bonten, W. G. Boersma et al., "Management of community-acquired pneumonia in adults: 2016 guideline update from the Dutch working party on antibiotic policy (SWAB) and Dutch association of chest physicians (NVALT)," Netherlands Journal of Medicine, vol. 76, no. 1, pp. 4-13, 2018.

[30] A. Black, "Community-acquired pneumonia-a clinical approach to assessment and management," South African Family Practice, vol. 50, no. 3, pp. 15-23, 2008.

[31] B. Regasa, "Aetiology of bacterial pathogens from adult patients with community-acquired pneumonia in Arba Minch hospital, South Ethiopia," Science, vol. 3, no. 3, pp. 33-36, 2014.

[32] B. Regasa, "Drug resistance patterns of bacterial pathogens from adult patients with pneumonia in Arba Minch hospital, South Ethiopia," Global Journal of Medical Research, vol. 14, no. 5, 2014.

[33] G. Bayisa, S. Suleman, K. Abdisa, and S. Fekadu, "Clinical outcome and in-vitro microbiological response of bacterial isolates to commonly prescribed antibiotics among hospitalized patients with community acquired pneumonia in Jimma University specialized hospital, Ethiopia," Indian Journal of Pharmacy Practice, vol. 8, no. 4, p. 183, 2015.

[34] B. Regasa, D. Yilma, T. Sewunet, and G. Beyene, "Antimicrobial susceptibility pattern of bacterial isolates from 
community-acquired pneumonia patients in Jimma University specialized hospital, Jimma, Ethiopia," Saudi Journal for Health Sciences, vol. 4, no. 1, p. 59, 2015.

[35] A. Shibabaw, T. Abebe, and A. Mihret, "Antimicrobial susceptibility pattern of nasal Staphylococcus aureus among Dessie Referral Hospital health care workers, Dessie, Northeast Ethiopia," International Journal of Infectious Diseases, vol. 25, pp. 22-25, 2014.

[36] J.-C. Lagier, S. Edouard, I. Pagnier, O. Mediannikov, M. Drancourt, and D. Raoult, "Current and past strategies for bacterial culture in clinical microbiology," Clinical Microbiology Reviews, vol. 28, no. 1, pp. 208-236, 2015.

[37] D. F. Postma, C. H. Van Werkhoven, L. J. R. Van Elden et al., "Antibiotic treatment strategies for community-acquired pneumonia in adults," New England Journal of Medicine, vol. 372, no. 14, pp. 1312-1323, 2015.

[38] M. Woodhead, F. Blasi, S. Ewig et al., "Guidelines for the management of adult lower respiratory tract infections-full version," Clinical Microbiology and Infection, vol. 17, pp. E1-E59, 2011.

[39] P. Tripathi and K. Dhote, "Lower respiratory tract infections: current etiological trends and antibiogram," Journal of Pharmaceutical and Biomedical Sciences, vol. 4, no. 3, pp. 249-255, 2014.

[40] A. Mokkapati and M. Yalamanchili, "Correlation of sputum gram's stain and culture in lower respiratory tract infections," IOSR Journal of Dental and Medical Sciences, vol. 8, no. 1, pp. 6-9, 2013.

[41] L. R. Grant, L. L. Hammitt, D. R. Murdoch, K. L. O'Brien, and J. A. Scott, "Procedures for collection of induced sputum specimens from children," Clinical Infectious Diseases, vol. 54, no. 2, pp. S140-S145, 2012.

[42] M. Cheesbrough, District Laboratory Practice in Tropical Countries, Cambridge University Press, Cambridge, UK, 2006.

[43] CLSI, Performance Standards for Antimicrobial Susceptibility Testing, Clinical and Laboratory Standards Institute, Wayne, PA, USA, 2019, http://www.clsi.org, 29th edition.

[44] A. Salami, P. Oluboyo, A. Akambi II, and E. Fawibe, "Bacterial pneumonia in the AIDS patients," West African Journal of Medicine, vol. 25, no. 1, pp. 1-5, 2006.

[45] C. Lin, H. Chen, P. He, Y. Li, C. Ke, and X. Jiao, "Etiology and characteristics of community-acquired pneumonia in an influenza epidemic period," Comparative Immunology, Microbiology and Infectious Diseases, vol. 64, pp. 153-158, 2019.

[46] M. Carugati, S. Aliberti, F. Blasi, A. Gori, and M. Restrepo, "Bacterial etiology of community-acquired pneumonia and appropriateness of empirical treatment recommendations: an international observational cohort study," American Thoracic Society, vol. B109, Article ID A4219, 2019.

[47] L. L. Tao, B. J. Hu, L. X He et al., "Etiology and antimicrobial resistance of community-acquired pneumonia in adult patients in China," Chinese Medical Journal, vol. 125, no. 17, pp. 2967-2972, 2012.

[48] S. Tchatchouang, A. Nzouankeu, S. Kenmoe et al., "Bacterial aetiologies of lower respiratory tract infections among adults in Yaoundé, Cameroon," BioMed Research International, vol. 2019, Article ID 4834396, 7 pages, 2019.

[49] I. Ahmad, S. Saleha, K. Rahim et al., "Awareness of diverse bacterial flora distribution causing pneumonia in Dir, Khyber Pakhtunkhwa, Pakistan," 2017.

[50] C. R. Ojha, N. Rijal, K. Khagendra et al., "Lower respiratory tract infections among HIV positive and control group in Nepal," Virus Disease, vol. 26, no. 1-2, pp. 77-81, 2015.
[51] Y.-T. Lin, Y.-Y. Jeng, T.-L. Chen, and C.-P. Fung, "Bacteremic community-acquired pneumonia due to Klebsiella pneumoniae: clinical and microbiological characteristics in Taiwan, 2001-2008," BMC Infectious Diseases, vol. 10, no. 1, p. 307, 2010.

[52] M. K. Paczosa and J. Mecsas, "Klebsiella pneumoniae: going on the offense with a strong defense," Microbiology and Molecular Biology Reviews, vol. 80, no. 3, pp. 629-661, 2016.

[53] J. Pham, T. Asif, and M. S. Hamarshi, "Community-acquired pneumonia with methicillin-resistant Staphylococcus aureus in a patient admitted to the intensive care unit: a therapeutic challenge," Cureus, vol. 10, no. 1, Article ID e2019, 2018.

[54] P. Korkmaz Ekren, B. Uysaler, N. Toreyin et al., "Risk factors for ventilator-associated pneumonia caused by MRSA in a respiratory intensive care unit," Clinical Diagnosis, Prediction and Outcomes of Lung Infections: American Thoracic Society, vol. A59, Article ID A2129, 2020.

[55] J. Almirall, M. Serra-Prat, I. Bolíbar, and V. Balasso, "Risk factors for community-acquired pneumonia in adults: a systematic review of observational studies," Respiration, vol. 94, no. 3, pp. 299-311, 2017.

[56] E. Prina, O. T. Ranzani, E. Polverino et al., "Risk factors associated with potentially antibiotic-resistant pathogens in community-acquired pneumonia," Annals of the American Thoracic Society, vol. 12, no. 2, pp. 153-160, 2015.

[57] I. Rivero-Calle, J. Pardo-Seco, P. Aldaz et al., "Incidence and risk factor prevalence of community-acquired pneumonia in adults in primary care in Spain (NEUMO-ES-RISK project)," BMC Infectious Diseases, vol. 16, no. 1, p. 645, 2016.

[58] K. Morimoto, M. Suzuki, T. Ishifuji et al., "The burden and etiology of community-onset pneumonia in the aging Japanese population: a multicenter prospective study," PLoS One, vol. 10, no. 3, 2015.

[59] A. A. Quartin, E. G. Scerpella, S. Puttagunta, and D. H. Kett, "A comparison of microbiology and demographics among patients with healthcare-associated, hospital-acquired, and ventilator-associated pneumonia: a retrospective analysis of 1184 patients from a large, international study," BMC Infectious Diseases, vol. 13, no. 1, p. 561, 2013.

[60] F. Pappoe, "Prevalence of bacterial pathogens isolated from sputum cultures of hospitalized adult patients with community-acquired pneumonia at the Cape Coast Teaching Hospital, Ghana," 2014.

[61] E. Muthumbi, B. S. Lowe, C. Muyodi, E. Getambu, F. Gleeson, and J. A. G. Scott, "Risk factors for community-acquired pneumonia among adults in Kenya: a case-control study," Pneumonia, vol. 9, no. 1, p. 17, 2017.

[62] A. Torres, W. E. Peetermans, G. Viegi, and F. Blasi, "Risk factors for community-acquired pneumonia in adults in Europe: a literature review," Thorax, vol. 68, no. 11, pp. 1057-1065, 2013.

[63] E. Simou, J. Britton, and J. Leonardi-Bee, "Alcohol and the risk of pneumonia: a systematic review and meta-analysis," BMJ Open, vol. 8, no. 8, 2018. 